\title{
Imido Cobalt Complexes with Imidyl Character
}

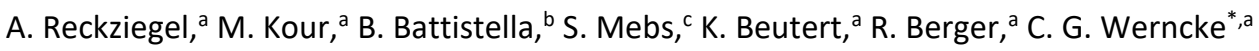

a) Philipps-University Marburg, Hans-Meerwein-Straße 4, D-35032 Marburg, Germany; b) Humboldt-Universität zu Berlin, Brook-TaylorStrasse 2, D-12489 Berlin, Germany; c) Freie Universität zu Berlin, Arnimallee 14, D-14195 Berlin-Dahlem, Germany

We report on the synthesis of a variety of trigonal imido cobalt complexes [Co(NAryl) $\left.L_{2}\right)^{-},\left(L=N(\text { Dipp)SiMe })_{3}\right.$, Dipp $=2,6$-diisopropylphenyl) bearing very long $\mathrm{Co}-\mathrm{N}_{\text {Aryl }}$ bonds of around $1.75 \AA$. The electronic structure was interrogated using a variety of physical and spectroscopic methods indicating the first authenticated examples of cobalt bound imidyl species. Computational studies corroborate these findings and reveal that the high-spin state of these complexes gives rise to unpaired spin-density on the imide nitrogen and leads to its imidyl character. Obtained complexes are capable of intermolecular $\mathrm{H}$ atom abstraction from $\mathrm{C}-\mathrm{H}$ bonds that yields the corresponding cobalt amides. Exchange of the Dipp-substituent on the imide by the smaller mesityl function (2,4,6-trimethylphenyl) effectuates the unexpected $\mathrm{Me}_{3} \mathrm{Si}$ shift from the ancillary ligand set to the imide nitrogen, followed by intramolecular $\mathrm{C}-\mathrm{H}$ bond activation

\section{Introduction}

Transition-metal bound imido units play an important role in coordination chemistry. The metal-imido bond is commonly described by a combination of a $\mathrm{M}-\mathrm{N} \sigma$-bond and backdonation from the $\mathrm{N}_{\text {imido }}$ lone pairs into empty d-orbitals with a nucleophilic nitrogen atom. ${ }^{[1]}$ In this capacity imido functions are capable of stabilizing high oxidation states and are usually found in early transition metal complexes. ${ }^{[2,3]}$ When going to late transition metals, the $d$-orbitals are successively filled and by that the possibility of back-bonding is reduced. In addition, the $\mathrm{M}-\mathrm{N}$ bond becomes more covalent due to energetic lowering of the d-orbitals. Consequently, the bond situation shifts away from a classical imido function to one with imidyl or even nitrene character of the nitrogen atom (Figure 1). ${ }^{[4-7]}$ Overall, this labilises the metal nitrogen bond of late $3 d-$ transition metal imido complexes which is increasingly exploited for catalytic formal transfer of the nitrene unit ([NR]) towards a substrate. This is especially of interest in the atom economic direct amination of unfunctionalised $\mathrm{C}-\mathrm{H}$ bonds, either via a stepwise $\mathrm{H}$ atom abstraction/radical recombination or a more concerted nitrene insertion mechanism. ${ }^{[8-18]}$ Despite the resulting high demand for understanding late $3 \mathrm{~d}$-transition imido metal species, comprehensive knowledge about the electronic and structural factors that contribute to their bond activation reactivity is still lacking. ${ }^{[19-42]}$ Most structurally characterised late-3d-transition metal imido complexes are found in a low-spin state which mitigates their reactivity and thus allowed for their isolation in the first place. To obtain higher-spin states and thus more reactive imido metal units, a weak ligand field of the ancillary ligands and an overall lowcoordinate environment of the metal showed to be useful in recent years. This was demonstrated for instance by the Betley group using the pyrromethane ligand framework ( $A^{\mathrm{M}}$, Figure 1) for iron to copper and by us for a two-coordinate cobalt silylamide fragment (B), leading to the isolation and characterisation of imido metal complexes which all are highly potent in $\mathrm{C}-\mathrm{H}$ bond activation. In the last few years further advances were made in the elucidation of more unusual bond situations via structural and spectroscopic identification of iron ${ }^{[34]}$ and nickel imidyl complexes (also referred to as metal iminyl species) ${ }^{[35]}$ or even a nitrene copper compound ${ }^{[38]}$ (Figure 1). A combination of various spectroscopic and magnetic methods as well as computational investigations was required to resolve the bonding situation.

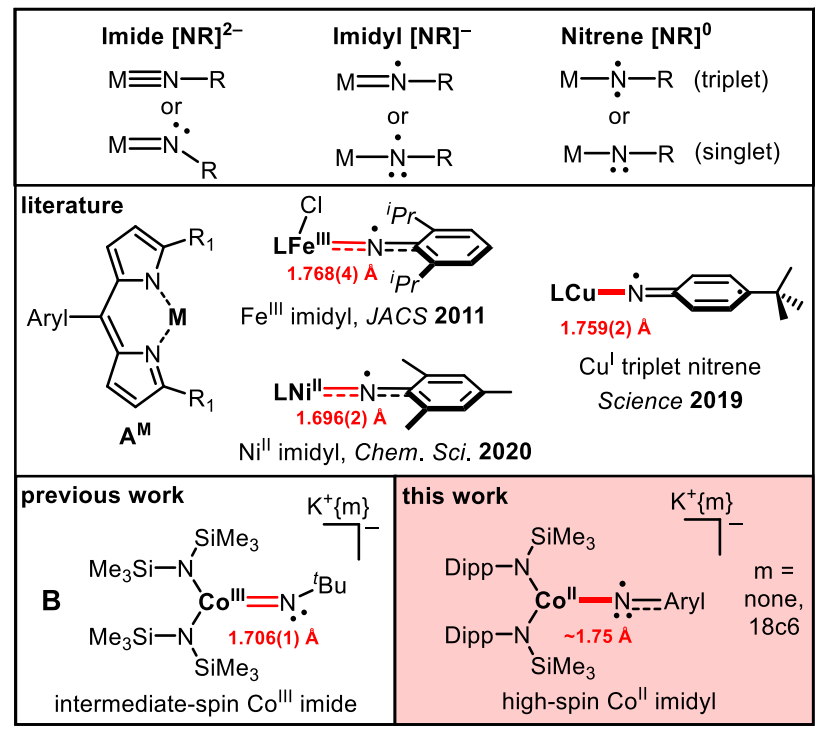

Figure 1. Top: Simplified description of the different bonding modes of [MNR] units. Middle: Bond lengths of known low coordinated nitrene/imidyl complexes $\left(A^{M}\right)$ and of the recently reported intermediate-spin imido cobalt (B) as well as the

Recently, we described a unique trigonal alkylimido cobalt(III) complex $\left[\mathrm{Co}\left(\mathrm{N}^{t} \mathrm{Bu}\right)\left(\mathrm{N}\left(\mathrm{SiMe}_{3}\right)_{2}\right)_{2}\right]^{-}(\mathrm{B})$, that exhibits one of the longest reported imido cobalt bonds (1.7067(12) $\AA$ ) and a very high $\mathrm{H}$ atom abstraction capability (Figure 1 ). ${ }^{[36]}$ The structural features and its remarkable reactivity were attributed to its intermediate spin state, unprecedented for an imido cobalt complex. Bearing in mind that the few known imidyl 3d-metal complexes contain aromatic $\mathrm{N}$-substituents we were naturally interested to know how the installation of an aromatic imido substituent would influence the electronic spin state and electronic structure of the imido cobalt unit. Herein we report on the synthesis of a variety of arylimido cobalt complexes, which bear $\mathrm{Co}-\mathrm{N}_{\text {imide }}$ bonds of around $1.75 \AA$, by far the longest reported in case of cobalt. Using a variety of analytical 
techniques (UV/Vis-, NMR-, EPR-spectroscopy, XANES, magnetic measurements) in conjunction with computational analysis, we conclude that these compounds are best described as imidyl cobalt(II) complexes. Obtained compounds show moderate intermolecular $\mathrm{H}$ atom abstraction capabilities owing to the steric congestion of the imido metal unit. Reduction of steric demand of the imide substituent results in an unexpected intramolecular shift of $\mathrm{a} \mathrm{Me}_{3} \mathrm{Si}$-unit of a transient arylimido species and subsequent intramolecular $\mathrm{C}-\mathrm{H}$ activation.

\section{Results and discussion}

Treatment of the quasilinear cobalt(I) complex $\left[\mathrm{Co}\left(\mathrm{N}\left(\mathrm{SiMe}_{3}\right)_{2}\right)_{2}\right]^{-}$with $\mathrm{Ph}-\mathrm{N}_{3}$ or Dipp- $\mathrm{N}_{3}$ (Dipp = 2,6-diisopropylphenyl), paralleling the synthesis of $\mathbf{B}$ using ${ }^{t} \mathrm{Bu}-\mathrm{N}_{3}$, gave only unselective reaction outcomes judging from ${ }^{1} \mathrm{H}-\mathrm{NMR}$ spectroscopy and yielded no identifiable products. As we attributed this to a higher reactivity of the arylimido cobalt unit, the sterically more encumbered cobalt(I) complex $\mathrm{K}\{18 \mathrm{c} 6\}\left[\mathrm{CoL}_{2}\right], \mathrm{K}\{18 \mathrm{c} 6\}[1],\left(\mathrm{L}=-\mathrm{N}(\mathrm{Dipp}) \mathrm{SiMe}_{3}\right)^{[43]}$ or its novel derivate K\{cryp.222\}[1] were employed to better shield the imido metal unit. Nonetheless, their reaction with $\mathrm{Ph}-\mathrm{N}_{3}$ remained inconclusive although immediate colour change under concomitant gas evolution was observed. In contrast, the reaction with Mes- $\mathrm{N}_{3}$ (Mes = 2,4,6-trimethylphenyl) led to the structural identification of the cobalt complex $K\{18 c 6\}[2]$ (Scheme 1).

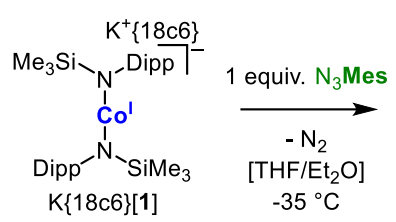
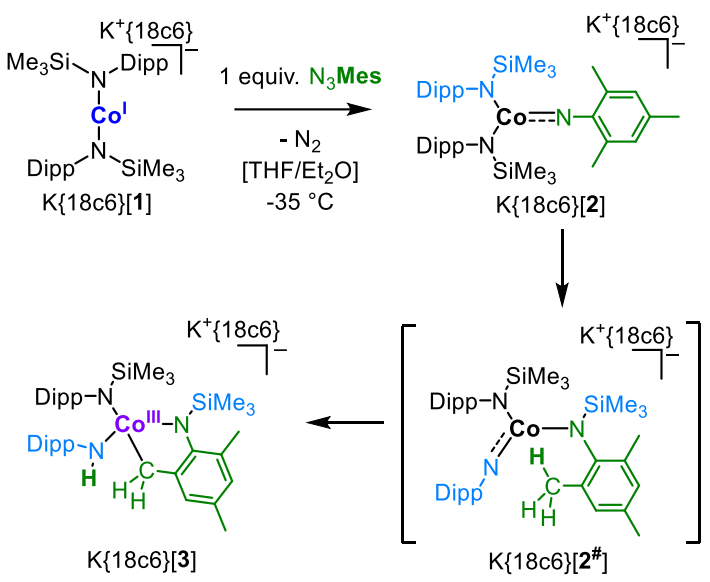

Scheme 1. Synthesis of [2] and formation of [3]- by $\mathrm{Me}_{3}$ Si-group shift followed by intramolecular hydrogen atom abstraction by the transient Dipp imide [ $\left.\mathbf{2}^{\#}\right]^{-}$(Dipp = 2,6-diisopropylphenyl).
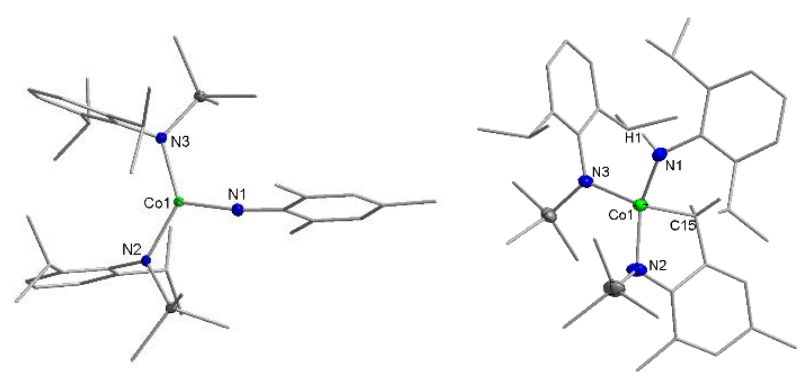

Figure 2. Molecular structure of $K\{18 c 6\}[2]$ and $K\{18 c 6\}[3]$ in the solid state. The $\mathrm{K}\{18 \mathrm{c} 6\}$ cation, solvent molecules as well as extraneous $\mathrm{H}$ atoms are omitted for clarity. Selected bond length $(A)$ and angles $\left(^{\circ}\right): \mathrm{K}\{18 \mathrm{c} 6\}[2]$ : Co1-N1 1.752(2); Co1N2 1.931(1); Co1-N3 1.927(1); N1-C1 1.344(2); Co1-N1-C1 168.9(1); K\{18c6\}[3]:
Co1-N1 1.897(3); Co1-N2 1.953(3); Co1-N3 1.977(3); Co1-C15 1.960(4).
X-ray diffraction analysis of $K\{18 c 6\}[2]$ showed a trigonal imido cobalt complex with an Co- $\mathrm{N}_{\text {imide }}$ bond length of $1.752(2) \AA$ (Figure 2). This is by at least $0.05 \AA$ longer than in all other known aryl imido cobalt complexes whose $\mathrm{Co}-\mathrm{N}_{\text {imide }}$ bond lengths range from $1.61 \AA$ to $1.70 \AA \AA$. ${ }^{[19,20,22,29-31,40]}$ This structural feature of [2]- resembles the abovementioned transition metal imidyl or nitrene complexes reported by Betley and co-workers which bear similar $\mathrm{M}-\mathrm{N}$ bond lengths $\left(\left[\mathrm{A}^{\mathrm{Fe}}\right]=1.768(4) \AA \AA^{\prime} ; \mathbf{A}^{\mathrm{Ni}}\right]=$ $\left.1.696(2) \AA ̊\left[A^{C u}\right]=1.759(2) \AA ̊\right)$ (Figure 1). For iron and nickel, they ascribed this to the presence of a metal bound radical imidyl unit with the radical character being partially distributed over the aromatic ring. For copper an admixture of contributions from a copper(II) imidyl and a dominant copper(I) singlet nitrene description was formulated. The $\mathrm{N}_{\text {imide }}$ Dipp unit in [2] ${ }^{-}$exhibits a shortened $\mathrm{N}-\mathrm{C}$ bond (1.344(2) $\AA$ ), whereas the first $\mathrm{C} 1-\mathrm{C}_{\text {Aryl }}$ bonds of the aromatic ring are slightly elongated ([2] $]^{-}: \mathrm{N}(\mathrm{Dipp}) \mathrm{SiMe}_{3}: 1.41 \AA$ 的. NMes: $1.43 \AA$ A). The $\mathrm{Co}-\mathrm{N}-\mathrm{C}_{\text {Mes }}$ axis is with $168.9(1)^{\circ}$ slightly bent whereas no residual proton could be found in the proximity of the $\mathrm{N}_{\text {imide }}$ atom on refinement of the X-ray diffraction data. The $\mathrm{Co}-\mathrm{N}_{\text {amide }}$ bond lengths of $\approx 1.93 \AA$ are similar to the related cobalt(III) imide $\left[\mathrm{Co}\left(\mathrm{N}^{t} \mathrm{Bu}\right)\left(\mathrm{N}\left(\mathrm{SiMe}_{3}\right)_{2}\right)_{2}\right]^{-}\left(\approx 1.94 \AA \AA^{-}{ }^{[36]} \mathrm{K}\{18 \mathrm{c} 6\}[2]\right.$ turned out to be highly reactive and could not be isolated in pure form as it facilitates intramolecular $\mathrm{C}-\mathrm{H}$ bond activation by $\mathrm{H}$ atom abstraction of one of the $\mathrm{Me}_{\mathrm{ipr}}$ groups. This led to the alkyl/amido cobalt(III) complex $\mathrm{K}\{18 \mathrm{c} 6\}[3]$, which co-crystallized in varying amounts, even when keeping the reaction time and temperature as short and low as possible. Closer inspection of the molecular structure of $K\{18 c 6\}[3]$ showed that the mesityl nitrogen is now carrying a $\mathrm{Me}_{3} \mathrm{Si}$ unit, which originated from the employed $-\mathrm{N}\left(\right.$ Dipp) $\mathrm{SiMe}_{3}$ ligand set. This likely occurs starting from [2] ${ }^{-}$which undergoes an unusual $\mathrm{Me}_{3} \mathrm{Si}$-group shift from the ancillary silyamide ligand to the mesityl imide unit. It is probably due to steric congestions and presence of a nucleophilic imide nitrogen in [2] ${ }^{-}$and would yield the transient cobalt complex $\left[\mathrm{CoL}(\mathbf{N D i p p})\left(\mathrm{N}(\mathrm{Mes}) \mathrm{SiMe}_{3}\right)\right]^{-},\left[\mathbf{2}^{\#}\right]^{-}$, with a Dipp imide function. and. Subsequently, intramolecular $\mathrm{H}$ atom abstraction and $\mathrm{Co}-\mathrm{C}$ bond formation leads to $\mathrm{K}\{18 \mathrm{c} 6\}[3]$. Intramolecular $\mathrm{C}-\mathrm{H}$ bond activation is usually an unwanted phenomenon for late $3 \mathrm{~d}$ metal imido complexes and mainly occurs under formal insertion of the [NR] unit into a $\mathrm{C}-\mathrm{H}$ bond of the imide substituent or the ancillary ligand set. ${ }^{[33,41]}$ The formation of a metal-carbon bond however was only observed for a mesityl imido cobalt(III) complex by Betley and coworkers ${ }^{[22]}$ and a transient aryl imido iron(II) complex by Cheng et al.. ${ }^{[42]}{ }^{1} \mathrm{H}$ NMR spectroscopic examination of the reaction of $[1]^{-}$with Mes- $\mathrm{N}_{3}$ revealed an immediate formation of [3]-, even at $-30^{\circ} \mathrm{C}$, which corroborated the labile nature of $[2]^{-}$. This hints to the high reactivity of the imido cobalt complex [2] $]^{-}$, which may be attributed to its elongated $\mathrm{Co}-\mathrm{N}_{\text {imide }}$ bond. ${ }^{[21,22,33,41]}$ Over the course of 12 hours decomposition of [3]- was further observed, prohibiting its isolation. To obtain a persistent aryl imido complex, the sterically more demanding Dipp $-\mathrm{N}_{3}$ was employed (Scheme 2). Its reaction with equimolar amounts of $\mathrm{K}\{\mathrm{m}\}[\mathbf{1}]$ at $-35^{\circ} \mathrm{C}$ in $\mathrm{Et}_{2} \mathrm{O} / \mathrm{THF}$ resulted in an immediate colour change from green to dark brown under concomitant gas evolution (probably $\mathrm{N}_{2}$ ) and yielded dark yellow crystals of $\mathrm{K}\{18 \mathrm{c} 6\}[4]$ and $\mathrm{K}\{\mathrm{crypt} .222\}[4]$, respectively (yields $>70 \%$ ). 


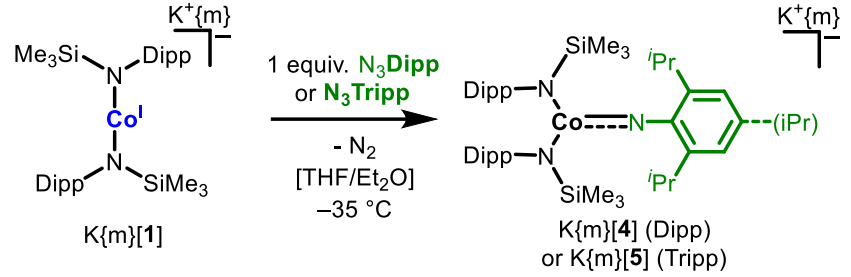

Scheme 2. Synthesis of $K\{m\}[4](m=$ none, crypt.222, 18c6) and $K\{m\}[5](m=$ none $18 \mathrm{c} 6$ ) starting from $\mathrm{K}\{\mathrm{m}\}[1]$ (Tripp $=2,4,6$-triisopropylphenyl).
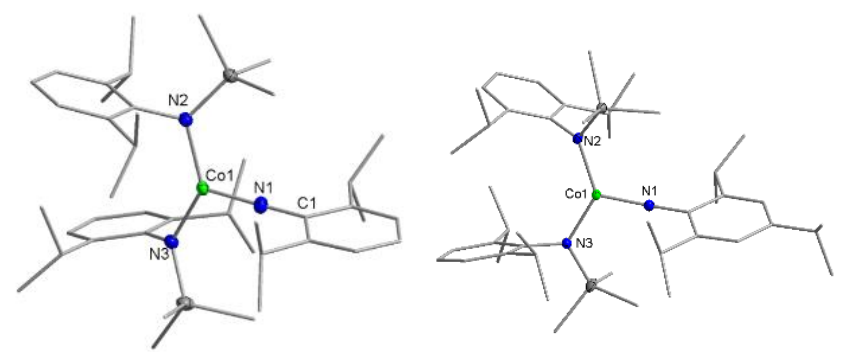

Figure 3. Molecular structure of $K\{18 c 6\}[4]$ (left) and $K\{18 c 6\}[5]$ (right) in the solid state. The $\mathrm{K}\{18 \mathrm{c} 6\}$ cation, solvent molecules as well as $\mathrm{H}$ atoms are omitted for clarity. Selected bond length $(A)$ and angles $\left({ }^{\circ}\right): \mathrm{K}\{18 \mathrm{c} 6\}[4]$ : Co1-N1: 1.751(2); Co1N2: 1.935(2); Co1-N3: 1.932(2); N1-C1: 1.347(2); Co1-N3-C31: 178.8(2) K\{18c6\}[5]: Co1-N1: 1.757(2); Co1-N2: 1.938(2); Co1-N3: 1.930(1); N1-C1 1.344(2); Co1-N3-C1: 171.9(1).

In solid state, the complex anions of both compounds exhibit similar structural metrics (Figure 3 ), for which the $K\{18 c 6\}[4]$ is chosen as a representative for discussion. The complex anion shows a trigonally coordinated cobalt ion with a $\mathrm{Co}-\mathrm{N}_{\text {imide }}$ bond length of 1.751(2) A which mimics the situation found for [2]-. In contrast to $[2]^{-}$the Co1-N1- $\mathrm{C}_{\mathrm{ipso}}$ bond angle is nearly linear $\left([4]^{-}: 178.8(2)^{\circ} ;[5]^{-}: 171.9(1)^{\circ}\right)$, owing to the more encumbered imide substituent. ${ }^{1} \mathrm{H}-\mathrm{NMR}$ spectroscopic examination of $[4]^{-}$in THF- $\mathrm{d}_{8}$ gave a variety of paramagnetically shifted signals, which could not be assigned due to large line broadening and low symmetry of the different nitrogen ligands. Determination of the magnetic moment in solution by the EVANS method gave $\mu_{\text {eff }}$ $=4.65 \mu_{\mathrm{B}}(\mathrm{K}\{\mathrm{crypt} .222\}[4])$ and $\mu_{\mathrm{eff}}=4.90 \mu_{\mathrm{B}}(\mathrm{K}\{18 \mathrm{c} 6\}[4])$. This is in approximate agreement with susceptibility measurements on $\mathrm{K}\{18 \mathrm{c} 6\}[4]$ in solid state $\left(\mu_{\text {eff }}=4.64 \mu_{\mathrm{B}}\right.$ at $\left.300 \mathrm{~K}\right)$ revealing a linear $1 / \chi$ vs $T$ slope with no apparent spin-crossover (Figure 4a). The magnetic susceptibility at room temperature is higher than that of the related $\left[\mathrm{Co}\left(\mathrm{N}^{t} \mathrm{Bu}\right)\left(\mathrm{N}\left(\mathrm{SiMe}_{3}\right)_{2}\right)_{2}\right]^{-}\left(\begin{array}{ll}3.52 & \mu_{\mathrm{B}}\end{array}\right)^{[36]}$, an intermediate spin ( $\mathrm{S}=1$ ) imido cobalt(III) complex, as well as of any other paramagnetic imido cobalt(III) complex. ${ }^{[22,37,41]}$ It is slightly lower than the spin only value of $4.92 \mu_{\mathrm{B}}$ of a quintet state, which might be indicative of a cobalt(II) ion weakly ferromagnetically coupled to an organic radical.

X-band EPR spectroscopy of $\mathrm{K}\{18 \mathrm{c} 6\}[4] \quad\left(\mathrm{d}_{10}-\mathrm{MeTHF}, 8 \mathrm{~K}\right)$ showed a broad signal at around $g_{1}=5.0$ and a sharper signal at $\mathrm{g}_{2}=2.05$, which is split due to the presence of hyperfinecoupling (Figure $\mathbf{4 b}$ ). For comparison, the corresponding amide [6]- (synthesis vide infra) was also examined. Its spectrum exhibits a single broad signal at around $\mathrm{g}_{1}=4.22$ (figure S28), which resembles the low-field portion of $K\{18 c 6\}[4]$. The experimental EPR data of [4]- could be satisfactorily modelled as a cobalt(II) ion bound to an organic radical anion (see Figure S27), whereas the high-field signal (Figure $\mathbf{4 b}$, inset) represents the imide based radical with coupling to cobalt, the imide nitrogen and one hydrogen atom (presumably $\mathrm{H}_{\text {para }}$ ). This signal is not well resolved due to the similar hyperfine coupling constants $\left(A\left({ }^{1} \mathrm{H}\right)=6.8 \mathrm{G}, \mathrm{A}\left({ }^{59} \mathrm{Co}\right)=4.3 \mathrm{G}, \mathrm{A}\left({ }^{14} \mathrm{~N}\right)=5.0 \mathrm{G}\right)$. As such EPR spectroscopy would confirm the notion of a weakly coupled cobalt(II)/imidyl system as indicated by the magnetic susceptibility measurements.
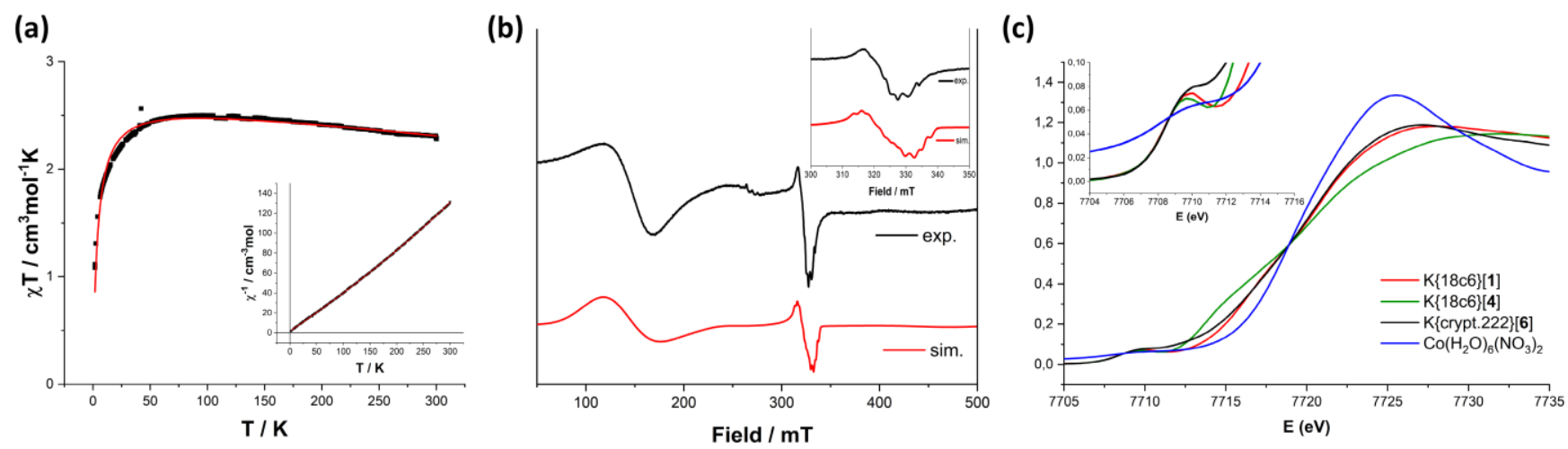

Figure 4. (a): variable-temperature susceptibility of $K\{18 \mathrm{c} 6\}[4]$ collected at $1 \mathrm{~T}$, with $\chi_{\mathrm{M}} T=2.33 \mathrm{~cm}^{3} \mathrm{~mol}^{-1} \mathrm{~K}(300 \mathrm{~K})$ and $n_{\text {eff }}=4.635(4) \mu_{\mathrm{B}}$. (b): X-Band $\mathrm{EPR}$ spectra of $\mathrm{K}\{18 \mathrm{c} 6\}[4]$ in frozen THF solution at $8 \mathrm{~K}$ (black) and simulated spectrum (red). $\mathrm{K}\{18 \mathrm{c} 6\}[4]: \mathrm{S}_{1}=3 / 2, \mathrm{~g}_{11}=5.0, \mathrm{~g}_{12}=1.4 ; \mathrm{S}_{2}=1 / 2, \mathrm{~g}_{21}=2.9, \mathrm{~g}_{22}=2.05, \mathrm{~A}_{22}\left({ }^{1} \mathrm{H}\right)=6.8 \mathrm{G}, \mathrm{A}_{22}\left({ }^{14} \mathrm{~N}\right)=5.0 \mathrm{G}, \mathrm{A}_{22}\left({ }^{59} \mathrm{Co}\right)=4.3$ G. (c): X-ray absorption spectroscopy (XANES): $K\{18 c 6\}[1]$ (red), $K\{18 c 6\}[4]$ (green), $K\left\{\right.$ crypt.222\}[6] (black), Coll reference $\mathrm{Co}\left(\mathrm{H}_{2} \mathrm{O}\right)_{6}\left(\mathrm{NO}_{3}\right)_{2}(\mathrm{green})$.

We further sought insight into the oxidation state of the metal using X-Ray absorption spectroscopy (Figure 4c). For that we examined the pre-edge and edge regions of the Co $1 \mathrm{~s}->3 \mathrm{~d}^{*}$ transition of $\mathrm{K}\{18 \mathrm{c} 6\}[4]$ as well as $\mathrm{K}\{18 \mathrm{c} 6\}[1]$ (h.s. Co') and K\{crypt.222\}[6] (h.s. Co"l) for comparison (in frozen THF solution).The X-Ray absorption spectra (XANES) show similar edge positions for all compounds as well as a considerable preedge feature. In some cases a shoulder is observed in the edgerise, which, together with a lacking edge-maximum, is indicative of a low local coordination symmetry for all complexes in solution. EXAFS generally supports the notion of a lowcoordinate environment for these complexes in solution however is ambiguous concerning the exact coordination number, probably due to additional solvent molecule coordination. Using cobalt oxides as references XANES suggests an oxidation state of about +2 for all compounds $(+1.7 \text { for } 6]^{-}$; +1.9 for $[1]^{-}$and $\left.[4]^{-}\right)$and thus implies a non-innocent character 
of the imido/imidyl unit as well as a charge balancing influence of the supporting aryl/silylamide ligands.

In attempts to probe the cobalt-imido bond IR and Raman spectra were recorded, using also partially ${ }^{15} \mathrm{~N}_{\text {imide }}$ labelled [4] ${ }^{-}$ $\left(1: 1{ }^{15} \mathrm{~N} /{ }^{14} \mathrm{~N}\right)$ to identify vibrations with significant $\mathrm{v}\left(\mathrm{Co}-\mathrm{N}_{\text {imide }}\right)$ character. ${ }^{[32,44,45]}$ As derived from the computational analysis (vide infra) its position is expected around $896 \mathrm{~cm}^{-1}$ and $889 \mathrm{~cm}^{-}$ ${ }^{1}$ for the ${ }^{15} \mathrm{~N}$ derivative, respectively. Similarly, the stretching bands of $\mathrm{N}-\mathrm{C}_{\text {Dipp }}$ and ${ }^{15} \mathrm{~N}-\mathrm{C}_{\text {Dipp }}$ should be observed at $1400 \mathrm{~cm}^{-}$ 1 and $1395 \mathrm{~cm}^{-1}$. However, no visible changes in neither the Raman nor the IR spectra were observed for modes belonging to the Co- $\mathrm{N}_{\text {imide }}$ or the $\mathrm{N}_{\text {imide }}-\mathrm{C}_{\text {Dipp }}$ bond (see ESI), which can be attributed to its computed small oscillator strength and might be lessened by a scrambling of the $\mathrm{Me}_{3} \mathrm{Si}$ group, as observed for $\mathrm{K}\{18 \mathrm{c} 6\}[2]$, which would dilute the ${ }^{15} \mathrm{~N}$ ratio within the imide function by up to $1 / 3$. To elaborate this possibility [1] $]^{-}$was reacted with Tripp- $\mathrm{N}_{3}$ (Tripp $=2,4,6$-tri-isopropylphenyl) which gave the imido complex [5]- (Co-N $_{\text {imide }} 1.757(2) \AA$ ). However, no scrambling of the $\mathrm{Me}_{3} \mathrm{Si}$ function could be observed over a prolonged time by means of X-Ray diffraction analysis and ${ }^{1} \mathrm{H}$ NMR spectroscopy. Given the comparably long $\mathrm{C}-\mathrm{N}_{\text {imide }}$ bonds found for complexes [2] $]^{-},[4]^{-}$, and [5] $]^{-}$of around $1.75 \AA$ as well as the previously reported $\mathrm{B}\left(\mathrm{Co}-\mathrm{N}^{t} \mathrm{Bu}: 1.707(1) \AA\right)^{[36]}$, we wanted to elaborate if this might be directly or indirectly a result of the anionic character of the imido complexes. Together with a low-spin trisphosphinoborate imido iron(II) complex by Brown et al.[46] this is a unique feature compared to all other structurally characterized transition metal imido complexes which are either neutral or cationic. As such we reacted the overall neutral cobalt(I) complex $\left[\mathrm{K}\left(\mathrm{CoL}_{2}\right)\right]^{[47]}$ with Dipp- $\mathrm{N}_{3}$ and Tripp $-\mathrm{N}_{3}$ which gave the respective imido complexes $K[4]$ and $\mathrm{K}[5]$, whose structures were confirmed via X-Ray analysis (Figure 5). In solid state the potassium cation interacts with the aromatic system of the imido ligand, whose coordination sphere is completed either by two diethyl ether molecules $(K[4])$, or by interaction with the aryl ring of the $-\mathrm{N}(\mathrm{Dipp}) \mathrm{SiMe}_{3}$ ligand of a neighbouring complex (K[5]) under formation of a polymeric chain. In comparison with the ion separated compounds $\mathrm{K}\{\mathrm{m}\}[4]$ and $\mathrm{K}\{\mathrm{m}\}[5]$ the direct potassium interaction and overall neutral state of has only minor impact on the central arylimido cobalt unit (K[4]: Co-Nimide 1.750 (3) $\AA$, $\mathrm{K}[5]$ Co- $\left.\mathrm{N}_{\text {imide }} 1.754(2) \AA\right)$. ${ }^{1} \mathrm{H}-\mathrm{NMR}$ spectra of the neutral complexes $\mathrm{K}[4]$ and $\mathrm{K}[5]$ in THF-[D8] are similar to those of the cation separated complexes $\mathrm{K}\{\mathrm{m}][4 / 5]$, indicating complete cation solvation. In contrast, using diethylether $K[4]$ and $K[5]$ showed distinctly different paramagnetic signals, speaking to a persistent potassium ion coordination to the complex anion in this solvent.
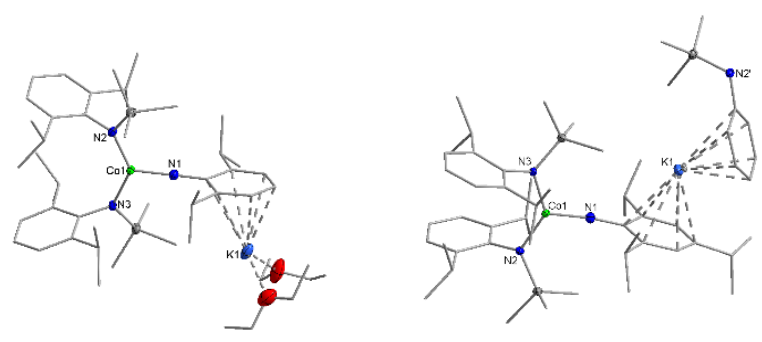

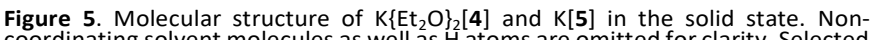
coordinating solvent molecules as well as $\mathrm{H}$ atoms are omitted for clarity. Selected
bond length $(\mathrm{A})$ and angles $\left({ }^{\circ}\right): \mathrm{K}[4]: \mathrm{Co} 1-\mathrm{N} 11.750(3)$; Co1-N2 1.916(2); Co1-N3 $1.920(2)$; N1-C1 1.338(4); Co1-N1-C1 174.9(3); K[5] Co1-N1 1.754(2); Co1-N2 $1.947(2)$; Co1-N3 1.927(2); N1-C1 1.351(2); Co1-N3-C1 173.5(2).

For corroboration and further understanding of the experimental findings we turned to computational analysis of the seminal $K\{18 c 6\}[4]$ as well as the corresponding cobalt(II) amide complex $\mathrm{K}\{18 \mathrm{c} 6\}[6]$ as an unambiguous reference in terms of the cobalt ions oxidation state $(+I I)$. Their experimental $\mathrm{X}$-ray single crystal data were used to construct input structures for subsequent quantum chemical studies. All electronic structures in their various possible spin states (high-, intermediate- and low-spin) were studied through dispersioncorrected density functional theory (DFT-D3) to account for dispersive intramolecular interactions. Various density functionals including the generalized gradient approximation (GGA) functionals BLYP and BP; hybrid functional B3-LYP; metahybrid functional M06; and the meta-GGA functional M06-L were used for determining the electronic energy differences between different spin states. For both compounds the highspin state was found to be the most stable for all functionals (Figure 6). As depicted in Figure 5, for K\{crypt.222\}[4] the intermediate spin is slightly higher in energy $(7 \mathrm{~kJ} / \mathrm{mol}$ to 38 $\mathrm{kJ} / \mathrm{mol}$ ), whereas the low-spin configuration is unfavoured $(67$ $\mathrm{kJ} / \mathrm{mol}$ to $157 \mathrm{~kJ} / \mathrm{mol}$ ).

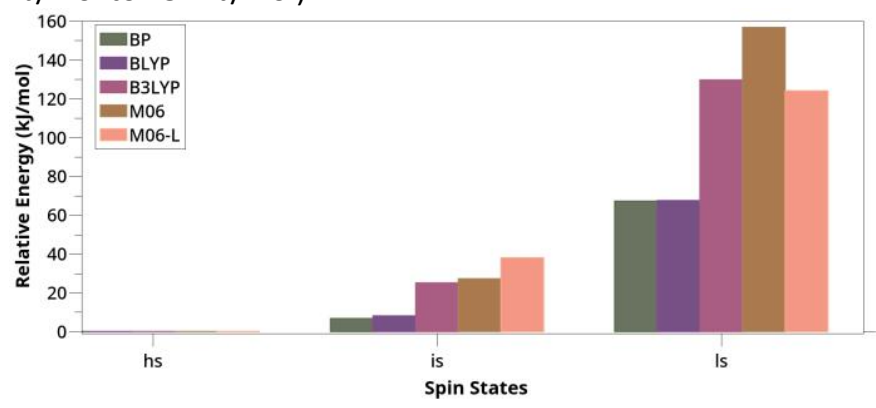

Figure 6. Relative energies of $[4]^{-}$in all spin states computed on DFT-D3 with Figure 6. Relative energies of [4]- in all spin states com
density functionals: BP, BLYP, B3-LYP, M06 and M06-L.

The differences in computed spin states of [4] $]^{-}$in comparison to the experimental data are visualized best using the Co- $\mathrm{N}_{\text {imide }}$ bond which shortens significantly from $1.75 \AA$ (high-spin), $1.72 \AA$ (intermediate-spin) to $1.67 \AA$ (low-spin) (Table 1). Thus, computational analysis supports for $\mathrm{K}\{18 \mathrm{c} 6\}[4]$ the notion of a high-spin compound (Co-Nimide 1.751(2) $\AA$ ). 
Table 1. Comparison of selected bond lengths and angles of [4] $]^{-}$calculated at the level of DFT-D3/M06-L with the experimental values.

\begin{tabular}{|c|c|c|c|c|}
\hline $\begin{array}{l}\text { Bond lengths }(\AA) \\
\text { and angles }\left({ }^{\circ}\right)\end{array}$ & $\begin{array}{l}\text { Experimental } \\
\text { values }\end{array}$ & h.s. $(S=2)$ & $\begin{array}{l}\text { Calculated } \\
\text { i.s. }(S=1)\end{array}$ & I.s. $(S=0)$ \\
\hline$r(\mathrm{Co} 1-\mathrm{N} 1)$ & 1.751 & 1.758 & 1.723 & 1.673 \\
\hline$r(\mathrm{Co} 1-\mathrm{N} 2)$ & 1.935 & 1.951 & 1.928 & 1.858 \\
\hline$r(\mathrm{Co} 1-\mathrm{N} 3)$ & 1.932 & 1.954 & 1.924 & 1.977 \\
\hline$r(\mathrm{~N} 1-\mathrm{C} 1)$ & 1.347 & 1.332 & 1.337 & 1.352 \\
\hline$\alpha(\mathrm{Co} 1-\mathrm{N} 1-\mathrm{C} 1)$ & 178.8 & 172.39 & 172.53 & 162.76 \\
\hline$\alpha(\mathrm{N} 2-\mathrm{Co} 1-\mathrm{N} 1)$ & 113.38 & 113.36 & 126.01 & 130.46 \\
\hline$\alpha(\mathrm{N} 2-\mathrm{Co} 1-\mathrm{N} 3)$ & 135.56 & 133.51 & 110.78 & 103.10 \\
\hline$\alpha(\mathrm{N} 1-\mathrm{Co} 1-\mathrm{N} 3)$ & 111.05 & 113.11 & 123.15 & 123.80 \\
\hline
\end{tabular}

h.s. $=$ high-spin, i.s. $=$ intermediate-spin, l.s. = low-spin.

Lowering the spin state leads also to slight bending of the Co$\mathrm{N}-\mathrm{C}$ axis by $10^{\circ}$ as well as compression of the $\mathrm{N}_{\text {Amide }}-\mathrm{Co}-\mathrm{N}_{\text {Amide }}$ angle, giving it a more $\mathrm{Y}$-shaped geometry. The $\mathrm{N}-\mathrm{C}_{\text {Aryl }}$ bond lengths, which are sometimes used as an indicator for the electronic structure of a metal bound aryl imide, ${ }^{[34]}$ are more or less unaffected by the spin state in the presented case. As a side-note, these computational results also validate in hindsight the previously made assignment of $\left[\mathrm{Co}\left(\mathrm{N}^{t} \mathrm{Bu}\right)\left(\mathrm{N}\left(\mathrm{SiMe}_{3}\right)_{2}\right)_{2}\right]^{-}(\mathrm{B})$ as an intermediate spin system, judging from its $\mathrm{Co}-\mathrm{N}_{\text {imide }}$ bond length (1.707(6) $\AA$ ). ${ }^{[36]}$ For the amide complex [6]- the high-spin state is also largely favoured (see ESI). Given the complexity of the system, the bond order is a valuable tool for considering the contributions made by occupied levels and understanding the bond character. As demonstrated in Figure 7, the higher the spin quantum number (or the higher the number of unpaired electrons), the lower the Wiberg Bond Index (WBI) of the Co$\mathrm{N}_{\text {imide }}$ bond, and vice versa.. The value of WBI for Co-N1 (highspin) is about 0.79 which reflects more single bond character. Besides, a rise in the WBI of Co1-N1 while moving towards lowspin (less unpaired electrons) is a clear indication of increased bond order i.e. higher possibility for imide character. Slightly higher Mulliken atomic charges on the cobalt ion in high-spin than for the other spins states could be observed, which also indicates a moderately decreased covalent character in the former case (Table 2).

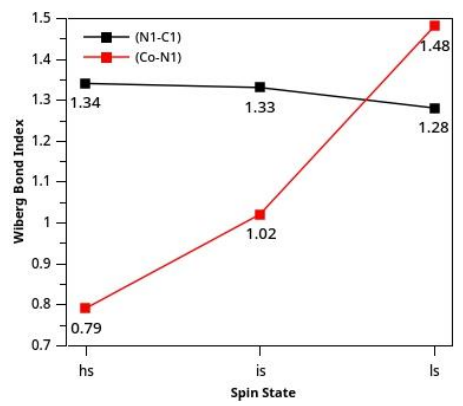

Figure 7. Calculated Wiberg bond indices of the selected bonds of complex [4]- (DFTD3/M06-L). Lines are drawn to guide the eye.
Table 2. Mulliken atomic charges and spin densities on the selected atoms of complex [4]- at the level of DFT-D3/M06-L.

\begin{tabular}{|c|c|c|c|c|}
\hline Entry & Atom & $\begin{array}{c}\text { h.s. } \\
\text { Mulliken atomic } \\
\text { charges } \\
\text { (spin density) }\end{array}$ & $\begin{array}{c}\text { i.s. } \\
\text { Mulliken atomic } \\
\text { charges } \\
\text { (spin density) }\end{array}$ & $\begin{array}{c}\text { I.s. } \\
\text { Mulliken atomic } \\
\text { charges } \\
\text { (spin density) }\end{array}$ \\
\hline 1 & Co1 & $\begin{array}{c}0.767 \\
(2.620)\end{array}$ & $\begin{array}{c}0.720 \\
(1.975)\end{array}$ & 0.688 \\
\hline 2 & N1 & $\begin{array}{l}-0.650 \\
(0.814)\end{array}$ & $\begin{array}{c}-0.657 \\
(-0.029)\end{array}$ & -0.649 \\
\hline 3 & N2 & $\begin{array}{c}-0.963 \\
(0.133)\end{array}$ & $\begin{array}{l}-0.940 \\
(0.086)\end{array}$ & -0.905 \\
\hline 4 & N3 & $\begin{array}{l}-0.968 \\
(0.128)\end{array}$ & $\begin{array}{c}-0.945 \\
(0.065)\end{array}$ & -0.923 \\
\hline & & & 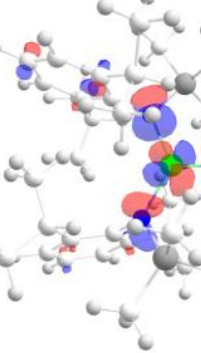 & \\
\hline
\end{tabular}

Figure 8. left: Total spin density distribution of the complex [4]- in high-spin state $(S=2)$. An isosurface value of 0.003 a.u. is chosen. right: SOMO of complex [4] (calculated with DFT-D3 using the density functional MO6-L).

Population analysis of the spin density, derived from the quantum chemical calculations, helps to delineate the possible imidyl character of complex [4] $]^{-}$. The spin density plot indicates not only enhanced involvement of the aryl imido unit but also of the ancillary ligand set (Figure $\mathbf{8}$, left). The SOMO is mainly localized on the cobalt atom as well as on the imide nitrogen (Figure 8, right). Further unpaired spin density is found at the ortho and para positions of the aromatic ring, but not the meta position. The SOMO reflects well the situation derived from EPR spectroscopy. SOMO-1, SOMO-2, SOMO-3 and HOMO are of mixed character and clearly show the involvement of the supporting aryl imido ligands as well (see ESI), which reveals their stabilizing role in this system and might also explain the ambiguous results from X-ray absorption spectroscopy. In comparison, for the intermediate-spin state $(S=1)$ the unpaired spin density is located almost exclusively on the cobalt ion (Table 2). Together with the increased WBI of 1.02 it gives the triplet state a distinct imide character. Overall, calculated electronic and structural parameters of [4]- accord with the experimental findings and thus validate the description of [4] ${ }^{-}$ as an imidyl complex, which is unprecedented for cobalt. It further shows that the high-spin state evokes the imidyl character and that the Co- $\mathrm{N}_{\text {imide }}$ bond length might act as an indicator for the spin state of such trigonal imido complexes of cobalt, and probably those of other late $3 \mathrm{~d}$-metals too.

Lastly, we examined the $\mathrm{C}-\mathrm{H}$ bond activation reactivity of [4] ${ }^{-}$ and $[6]^{-}$. Given their complex ${ }^{1} \mathrm{H}$ NMR spectroscopic features, which hampers such a study, we synthesized first the respective expected cobalt(II) amides, which would result from formal $\mathrm{H}$ atom abstraction from suitable substrates. 


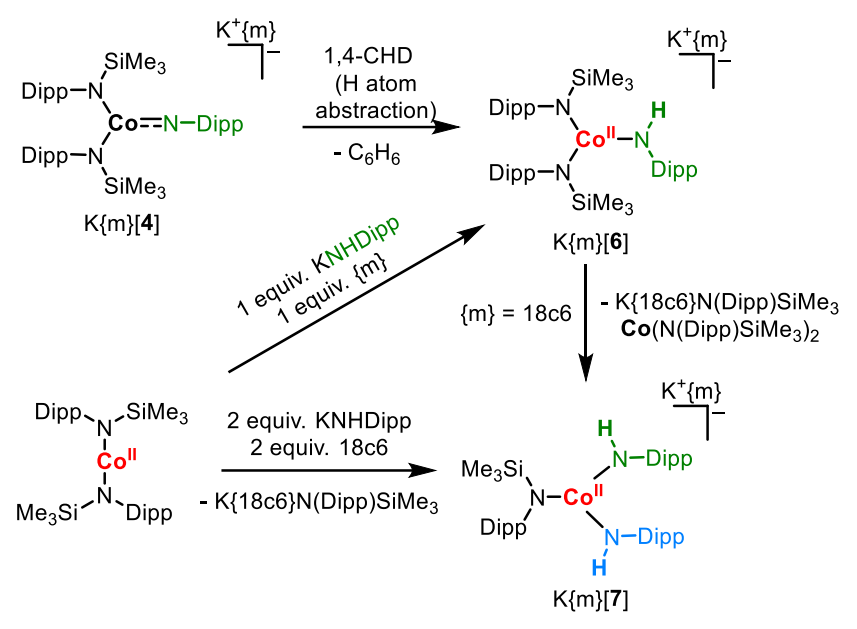

Scheme 3. H-Atom abstraction from 1,4-cyclohexadiene (1,4-CHD) by [4] and ligand exchange reactivity of the resulting [6] $]^{-}$giving [7] ${ }^{-}$as well as their independent synthesis.
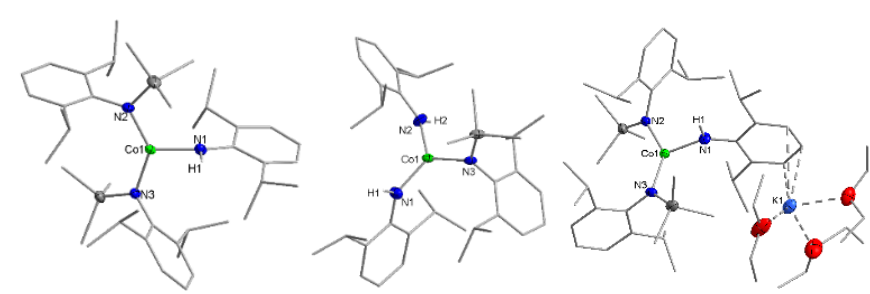

Figure 9. Molecular structure of the anion of $K\{$ crypt.222\}[6] (left), $K\{18 c 6\}[7]$

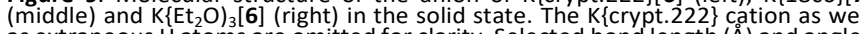
as extraneous $\mathrm{H}$ atoms are omitted for clarity. Selected bond length $(A)$ and angle $\left({ }^{\circ}\right)$ : K\{crypt.222\}[6]: Co1-N1 1.921(2); Co1-N2 1.947(2); Co1-N3 1.949(2); N1-C1 1.375(3); Co1-N1-C1 141.2(2); K\{18c6\}[7]: Co1-N1 1.919(3); Co1-N2 1.926(3); N1-C1 1.355(3); Co1-N1-C1 148.4(2)

As such $\left[\mathrm{CO}^{\prime \prime} \mathrm{L}_{2}\right]$ was reacted with KNHDipp in the presence of either crypt.222 or 18 -crown-6 (Scheme 3). Direct ${ }^{1} \mathrm{H}-\mathrm{NMR}$ spectroscopy examination of the reaction of suggested a similar reaction pathway in both cases, although only in case of

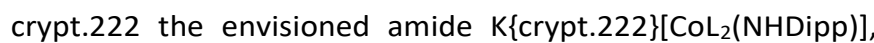
$\mathrm{K}\{\mathrm{crypt}\}[6]$, could be isolated as orange crystals (58\%). For 18 crown-6 green crystals were obtained besides orange $\mathrm{K}\{18 \mathrm{c} 6\}[6]$ which were identified as $\mathrm{K}\{18 \mathrm{c} 6\}\left[\mathrm{CoL}(\mathrm{NHDipp})_{2}\right]$, $\mathrm{K}\{18 \mathrm{c} 6\}[7]$. The latter was apparently product of amide ligand scrambling which was confirmed by concomitant formation of $K\{18 c 6\}[L)]$ and $\left[\mathrm{CoL}_{2}\right]$. The formation of $K\{18 c 6\}[7]$ is likely mediated by the $K\{18 \mathrm{c} 6\}$ counter ion which in contrast to the potassium ion encapsulated in crypt.222 can act as a Lewis acid. $\mathrm{K}\{18 \mathrm{c} 6\}[7]$ can deliberately be isolated via the reaction of [ $\left.\mathrm{CoL}_{2}\right]$ with two equivalents of $K\{18 \mathrm{c} 6\}[\mathrm{NHDipp}]$. In comparison with $[4]^{-}$the central Co-N bond in [6] ${ }^{-}$is elongated to $1.921(2) \AA\left([4]^{-}\right.$ : $1.751(2) \AA$ ) and in the range of cobalt(II) amide bonds (Figure 9). ${ }^{[48,49]}$ In addition, the Co- $\mathrm{N}-\mathrm{C}_{\text {Aryl }}$ bond axis is with $141.2(2)^{\circ}$ clearly bent $\left([4]^{-}: 178.8(2)^{\circ}\right)$. A similar bonding situation of the amide ligands could be seen for [7] $]^{-}$. The reaction of [Co" $\left.\mathrm{L}_{2}\right]$ with KNHDipp in the absence of a potassium masking agent yielded cleanly [KCo" $\mathrm{L}_{2}$ (NHDipp)] (K[6]). X-Ray diffraction analysis showed an interaction of the potassium ion with the aromatic ring of the primary amide, comparable to $K[4]$. The magnetic moments of $\mathrm{K}\{\mathrm{m}\}[6]\left(\mathrm{m}=\right.$ none $: \mu_{\text {eff }}=4.26 \mu_{\mathrm{B}}$; crypt.222: $\mu_{\text {eff }}=$ $\left.4.59 \mu_{\mathrm{B}}\right)$ and $\mathrm{K}\{18 \mathrm{c} 6\}[7]\left(\mu_{\text {eff }}=4.28 \mu_{\mathrm{B}}\right)$ in solution are in the expected range of high-spin cobalt(II) complexes $\left(\mu_{\text {s.o. }}(3 / 2)=\right.$

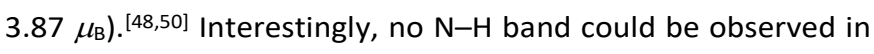
the IR spectra of neither $[6]^{-}$nor []$^{-}$showing that IR spectroscopy is in our case an inept tool to identify the presence of a metal bound amide. Having understood the intricacies of these amido complexes we returned to the K\{crypt.222\}[4] mediated $\mathrm{C}-\mathrm{H}$ activation. ${ }^{1} \mathrm{H}$ NMR spectroscopic examination of the reaction of $[4]^{-}$with 1,4 -cyclohexadiene $(1,4-\mathrm{CHD})$ that bears a moderate $\mathrm{C}-\mathrm{H}$ bond strengths of $76 \pm 2 \mathrm{kcal} / \mathrm{mol}$ ) showed clean formation of [7] $]^{-}$and benzene, which indicated successful $\mathrm{H}$ atom abstraction, and as well as the mentioned ligand scrambling. The reaction of the neutral complex $\mathrm{K}[4]$ with $1,4-\mathrm{CHD}$ led only to minor formation of $K[6]$, as well as decomposition of the cobalt complexes. The intermolecular C$\mathrm{H}$ atom abstraction capability is thereby significantly smaller compared to the seminal $\left[\mathrm{Co}\left(\mathrm{N}^{t} \mathrm{Bu}\right)\left(\mathrm{N}\left(\mathrm{SiMe}_{3}\right)_{2}\right)_{2}\right]^{-}$(B). This can be attributed to the sterically shielded imide nitrogen in [4] that enabled its isolation.

\section{Conclusions}

We reported the synthesis and characterisation of a variety of anionic and formally neutral trigonal arylimido cobalt complexes via reaction of quasilinear cobalt(I) silylamides with aryl azides. These exhibit by far the longest reported $\mathrm{Co}-\mathrm{N}_{\text {imide }}$ bond lengths of around $1.75 \AA$. The use of X-Ray diffraction analysis, IR-, Raman-, EPR- and X-Ray absorption spectroscopy, in conjunction with computational analysis, led to their description as high-spin imido cobalt complexes with significant imidyl character, which is unprecedented for cobalt. The imido cobalt complexes can facilitate $\mathrm{H}$ atom abstraction from moderately strong $\mathrm{C}-\mathrm{H}$ bonds which resulted in the formation of cobalt(II) amido complexes. With the smaller mesityl azide a highly labile mesitylimido cobalt complex was observed which underwent an unusual $\mathrm{Me}_{3} \mathrm{Si}$-group shift from the ancillary amide ligand set to the imide nitrogen, Subsequently, intramolecular $\mathrm{C}-\mathrm{H}$ activation via formal addition of the $\mathrm{C}-\mathrm{H}$ bond along the newly formed $\mathrm{Co}-\mathrm{N}_{\text {imide }}$ bond could be observed in this case.

\section{Acknowledgement}

Funding by the Deutsche Forschungsgemeinschaft (DFG) is gratefully acknowledged: grants WE 5627/4-1 (C. G. W.). M. K. and R. B. thank the Center for Scientific Computing (CSC) Frankfurt for computer time and R. K. Bansal and M. Holthausen for discussion.

\section{Conflicts of interest}

There are no conflicts to declare.

\section{References}

[1] T. R. Cundari, J. Am. Chem. Soc. 1992, 114, 7879.

[2] C. Lorber, Coord. Chem. Rev 2016, 308, 76.

[3] D. J. Mindiola, Acc. Chem. Res. 2006, 39, 813. 
[4] A. I. Olivos Suarez, V. Lyaskovskyy, J. N. H. Reek, J. I. van der Vlugt, B. de Bruin, Angew. Chem. Int. Ed. 2013, 52, 12510.

[5] K. Ray, F. Heims, F. F. Pfaff, Eur. J. Inorg. Chem. 2013, 2013, 3784.

[6] R. Eikey, Coord. Chem. Rev 2003, 243, 83.

[7] J. F. Berry, Comment. Inorg. Chem. 2009, 30, 28.

[8] Y. Park, Y. Kim, S. Chang, Chem. Rev. 2017, 117, 9247.

[9] H. Lu, X. P. Zhang, Chem. Soc. Rev. 2011, 40, 1899.

[10] Florence Collet, Robert H. Dodd, Philippe Dauban, Chem. Commun. 2009, 5061.

[11] V. Bagchi, A. Kalra, P. Das, P. Paraskevopoulou, S. Gorla, L. Ai, Q. Wang, S. Mohapatra, A. Choudhury, Z. Sun, T. R. Cundari, P. Stavropoulos, ACS Catal. 2018, 8, 9183.

[12] P. F. Kuijpers, J. I. van der Vlugt, S. Schneider, B. de Bruin, Chem. Eur. J. 2017, 23, 13819.

[13] D. N. Zalatan, J. Du Bois in Metal-Catalyzed Oxidations of $\mathrm{C}-\mathrm{H}$ to $C-N$ Bonds, pp. 347-378.

[14] Y. Dong, C. J. Lund, G. J. Porter, R. M. Clarke, S.-L. Zheng, T. R. Cundari, T. A. Betley, J. Am. Chem. Soc. 2021.

[15] R. Breslow, S. H. Gellman, J. Chem. Soc. 1982, 1400.

[16] R. Breslow, S. H. Gellman, J. Am. Chem. Soc. 1983, 105, 6728.

[17] M. M. Díaz-Requejo, T. R. Belderraín, M. C. Nicasio, S. Trofimenko, P. J. Pérez, Journal of the American Chemical Society 2003, 125, 12078.

[18] D. Hazelard, P.-A. Nocquet, P. Compain, Org. Chem. Front. 2017, 4, 2500.

[19] T. A. Betley, J. C. Peters, J. Am. Chem. Soc. 2003, 125, 10782.

[20] X. Hu, K. Meyer, J. Am. Chem. Soc. 2004, 126, 16322.

[21] L. Zhang, Y. Liu, L. Deng, J. Am. Chem. Soc. 2014, 136, 15525.

[22] E. R. King, G. T. Sazama, T. A. Betley, J. Am. Chem. Soc. 2012, $134,17858$.

[23] J. Du, L. Wang, M. Xie, L. Deng, Angew. Chem. Int. Ed. 2015, 54, 12640.

[24] B. Wu, R. Hernández Sánchez, M. W. Bezpalko, B. M. Foxman, C. M. Thomas, Inorg. Chem. 2014, 53, 10021.

[25] R. E. Cowley, R. P. Bontchev, J. Sorrell, O. Sarracino, Y. Feng, H. Wang, J. M. Smith, J. Am. Chem. Soc. 2007, 129, 2424.

[26] Y. Liu, L. Deng, J. Am. Chem. Soc. 2017, 139, 1798.

[27] J. J. Scepaniak, J. A. Young, R. P. Bontchev, J. M. Smith, Angew. Chem. Int. Ed. 2009, 48, 3158.

[28] D. T. Shay, G. P. A. Yap, L. N. Zakharov, A. L. Rheingold, K. H. Theopold, Angew. Chem. Int. Ed. 2006, 45, 7870.

[29] X. Dai, P. Kapoor, T. H. Warren, J. Am. Chem. Soc. 2004, 126 4798.

[30] D. M. Jenkins, T. A. Betley, J. C. Peters, J. Am. Chem. Soc. 2002, $124,11238$.

[31] C. Jones, C. Schulten, R. P. Rose, A. Stasch, S. Aldridge, W. D. Woodul, K. S. Murray, B. Moubaraki, M. Brynda, G. La Macchia, L. Gagliardi, Angew. Chem. Int. Ed. 2009, 48, 7406.

[32] M. P. Mehn, S. D. Brown, D. M. Jenkins, J. C. Peters, L. Que, Inorg. Chem. 2006, 45, 7417.

[33] S. Thyagarajan, D. T. Shay, C. D. Incarvito, A. L. Rheingold, K. H. Theopold, J. Am. Chem. Soc. 2003, 125, 4440.

[34] D. A. lovan, T. A. Betley, J. Am. Chem. Soc. 2016, 138, 1983.

[35] Y. Dong, J. T. Lukens, R. M. Clarke, S.-L. Zheng, K. M. Lancaster, T. A. Betley, Chem. Sci. 2020, 123, 4623.

[36] A. Reckziegel, C. Pietzonka, F. Kraus, C. G. Werncke, Angew. Chem. Int. Ed. 2020.

[37] Y. Baek, T. A. Betley, J. Am. Chem. Soc. 2019, 141, 7797.

[38] K. M. Carsch, I. M. DiMucci, D. A. Iovan, A. Li, S.-L. Zheng, C. J. Titus, S. J. Lee, K. D. Irwin, D. Nordlund, K. M. Lancaster, T. A. Betley, Science 2019, 365, 1138.

[39] Y. Baek, E. T. Hennessy, T. A. Betley, J. Am. Chem. Soc. 2019.
[40] Y. Liu, J. Du, L. Deng, Inorg. Chem. 2017, 56, 8278.

[41] D. T. Shay, G. P. A. Yap, L. N. Zakharov, A. L. Rheingold, K. H. Theopold, Angew. Chem. 2005, 117, 1532.

[42] J. Cheng, J. Liu, X. Leng, T. Lohmiller, A. Schnegg, E. Bill, S. Ye, L. Deng, Inorg. Chem. 2019, 58, 7634.

[43] C.-Y. Lin, J. C. Fettinger, F. Grandjean, G. J. Long, P. P. Power, Inorg. Chem. 2014, 53, 9400.

[44] J. Manna, R. F. Dallinger, V. M. Miskowski, M. D. Hopkins, J. Phys. Chem. B 2000, 104, 10928.

[45] J. H. Osborne, W. C. Trogler, Inorg. Chem. 1985, 24, 3098.

[46] S. D. Brown, J. C. Peters, J. Am. Chem. Soc. 2005, 127, 1913.

[47] R. Weller, I. Müller, C. Duhayon, S. Sabo-Etienne, S. Bontemps, Werncke, C., Gunnar, submitted.

[48] A. Massard, P. Braunstein, A. A. Danopoulos, S. Choua, P. Rabu, Organometallics 2015, 34, 2429.

[49] C. B. Hansen, R. F. Jordan, G. L. Hillhouse, Inorg. Chem. 2015, $54,4603$.

[50] A. Eichhöfer, Y. Lan, V. Mereacre, T. Bodenstein, F. Weigend, Inorg. Chem. 2014, 53, 1962. 